\title{
ACTINOMICOSE TORACOVERTEBRAL COM PAQUIMENINGITE E COMPRESSAO MEDULAR
}

\author{
JOSE LAMARTINE DE ASSIS * \\ CONSTANTINO MIGNONE **
}

Entre nós é de ocorrência relativamente rara a actinomicose do sistema nervoso central. Nossa casuística é ainda bastante pobre, mesmo considerando outras micoses. Pouco numerosa, também, é a literatura estrangeira. As referências encontradas nos tratados clássicos deixam muito a desejar. De acôrdo com os dados fornecidos por Almeida e Lacaz ${ }^{1}$, em um total de 144 casos de micetomas observados no Brasil, apenas num grupo de 15 havia localização na cabeça e pescoço (incluindo localização na língua, bochechas e encéfalo). Maffei ${ }^{2}$, em 16000 autópsias, só encontrou 4 casos de lesões actinomicóticas do sistema nervoso central. Em 1934, Ottoni de Rezende, citado por La$\mathrm{caz}^{3}$, descreveu um caso de actinomicose da região orbitária esquerda com invasão endocraniana. Em 1939, Gonzales Torres 4 estudou 2 casos de actinomicose do sistema nervoso central, casos êstes que foram incluídos na estatística de Maffei 2. No entanto, pelo menos em nosso meio, são bastante freqüentes as dermatopatias e mesmo as lesões ostearticulares e viscerais dessa natureza. Tal fato sugere a hipótese de terem os fungos pouca afinidade pelo tecido nervoso. Também é possível que o acometimento dêsse tecido seja mais freqüente e, por circunstâncias diversas, seu diagnóstico clínico ou anatômico poucas vezes seja confirmado. Temos a impressão de que mais intima colabal Tolosa).

* Assistente de Neurologia na Fac. Med. Univ. São Paulo (Prof. Adher-

** Docente-livre e assistente do Departamento de Anatomia Patológica da Fac. Med. Univ. São Paulo (Prof. L. da Cunha Motta).

1. Almeida, F. e Lacaz, C. S. - Actinomicose cervicofacial. Arq. Cir. Clin. e Exp., 4:560-577 (dezembro) 1940.

2. Maffei, W. E. - Micoses do sistema nervoso. An. Fac. Med. Univ. São Paulo, 19:297, 1943.

3. Lacaz, C. S. - Contribuição para o estudo dos actinomicetos produtores de micetomas. Tese de docência, São Paulo, 1945.

4. Gonzales Torres, G. M. - Estudo sôbre as lesões histopatológicas de dois casos de actinomicose do sistema nervoso central. Ann. Fac. Med. Univ. São Paulo, 15:235, 1939. 
boração entre clínicos, especialistas e laboratoristas viria tornar menos raros os achados de lesões micóticas do sistema nervoso. Do ponto de vista prático, diante de processos neurológico de etiologia obscura e com manifestações focais, a hipótese de micose não deve ser esquecida.

A actino e blastomicose são as que com maior freqüência podem localizar-se no neuraxe. Zachary Cope, citado por Eckoff e Lond ${ }^{5}$, sugere a propagação pela nasofaringe e nervos olfativos, pela via sangüínea (abscessos metastáticos), e através de lesões ósseas e foramens da base do crânio. Neste último caso, a actinomicose se coloca em primeiro plano, por isso que é a mais osteófila de tôdas as micoses segundo Lacaz ${ }^{6}$. As lesões vertebrais actinomicóticas sendo rarefacientes e altamente destrutivas, têm grande probabilidade de atingir a medula e, daí, o interêsse que apresentam para a patologia nervosa. Nestas circunstâncias, há a possibilidade de ser confundida a espondilite actinomicótica com o mal de Pott. Realmente, a evolução clínica dessas duas espondilopatias é pràticamente a mesma. Por êsse fato, vários autores procuram diferençá-las radiològicamente. Meyer e Gall ${ }^{7}$, que estudaram 47 casos de espondilite actinomicótica, julgam que esta provoque maior erosão da porção cortical das vértebras e mais intensa destruição óssea, geralmente não determinando deformidade angular. $\mathrm{Cope}^{8}$ afirma que o Actinomyces prefere a parte cortical, lâminas, facetas articulares e apófises, enquanto a tuberculose tem afinidade pelo disco intervertebral. A actinomicose vertebral raramente é primitiva, sendo em geral propagada de lesões do mediastino, pleura, bucofaringe, pulmões e órgãos peritoniais. As lesões são predominantemente rarefacientes e destrutivas e poupam o disco intervertebral. A evolução clínica da moléstia é idêntica à do mal de Pott: rápida, sendo muito alta a mortalidade.

$O$ interêsse do caso que ilustra êste trabalho reside não só no quadro clínico, na localização pulmonar primitiva do processo, na sua relativa raridade, como também por se tratar de um caso anátomo-clínico acompanhado durante longo tempo de sua evolução. Por outro lado, a

5. Eckoff, N. L. e Lond, M. - Actinomycosis of the Central Nervous System. Report of two cases. Lancet, 1:7-8 (janeiro) 1941.

6. Lacaz, C. S. - Contribuição para o estudo das micoses com lesões ostearticulares. Trabalho premiado pela Associação Paulista de Medicina, em 1941, com o prêmio A. C. de Camargo. Separata. Gráfica e Editora Edigraf Ltd., São Paulo, 1945.

7. Meyer, M. e Gall Monroe - Mycosis of the vertebral column. A review of the literature. J. Bone a. Joint Surg., 17 (outubro) 1935. 1938.

8. Cope, Z. - Actinomycosis. Oxford Medical Publications, Londres, 
difusão da infecção se fêz de modo bastante rápido e grave com manifestações clínicas polimorfas; além disso, evidenciaram-se provas clínicas e laboratoriais de acometimento secundário do sistema nervoso central, condensadas numa síndrome compressiva medular frusta. $\mathrm{Fi}$ nalmente, o Actinomyces isolado foi identificado como sendo o Actinomyces israelli, atualmente chamado Cohnistreptotrix israelli. Esse fungo, apesar de já ter sido encontrado em muitos casos de actinomicose humana em várias partes do mundo, nunca o fôra aqui em $\mathrm{S}$. Paulo, o que vem aumentar o interêsse da parte micológica. Trata-se de um cogumelo que vive saprofiticamente em cáries dentárias e amígdalas. E' possível que muitos casos de formas cervical e pulmonar da actinomicose sejam devidas a êste parasito. Seus filamentos são em forma de $\mathrm{V}$ ou $\mathrm{Y}$ e não se desenvolvem nos meios habituais de cultura. Sua atividade bioquímica $e$ muito reduzida. As inoculações por via peritoneal produzem pequenos abscessos no peritônio, mas o fungo não se dissemina.

\section{OBSERVAÇAO *}

A. M. P., português, com 52 anos, branco, casado, lavrador, procedente de Apucaranã, no norte do Estado do Paraná, internado na $4 .^{a}$ Enfermaria de $\mathrm{Me}$ dicina de Homens da Sta. Casa de São Paulo (Serviço do Prof. Adolfo Lindenberg). Acha-se doente há 2 anos e meio. Queixa-se de dôres no dorso e fraqueza geral. A moléstia iniciou-se de modo insidioso, com processo ganglionar no lado direito do pescoço, que se abriu na pele e se fistulizou. Alguns meses depois, começou a ter dôres vagas no dorsa, com exacerbações variáveis, mas progressivamente crescentes, até que, há cêrca de 10 meses, se definiram perfeitamente em raqui e radiculalgias dorsais com propagação em faixa; as dôres aumentavam com a tosse e espirro. Durante êsse tempo, foi perdendo apetite $\mathrm{e}$ pèso, as pernas foram-se enfraquecendo e dificultando progressivamente a deambulação. As lesões cutâneas foram-se estendendo e se multiplicando na face posterior e anterior do tórax. Sobreveio tosse e expectoração amarelada, por vezes hemoptoica; cêrca de 40 dias após a internação, isto é, em princípio de setembro de 1943, a marcha tornou-se impossível e a movimentação no leito quase nula em vista das fortes algias dorsais. Por essa ocasião, apareceram sinais de insuficiência cardíaca e respiratória (dispnéia contínua, cianose, estase nas bases pulmonares, congestão do fígado e edema nas partes declives).

Exame físico geral c especial - Indivíduo do tipo longilíneo, caquético e em estado de profundo abatimento moral. Apresenta-se acamado, em decúbito late-

* Agradecemos ao Dr. Domingos de Oliveira Ribeiro, livre-docente e assistente de Clínica Dermatológica da Fac. Med. Univ. São Paulo (Serviço do Prof. Aguiar Pupo) e V. Arruda Zamith, assistente voluntário da Clínica Dermatológica da Sta. Casa de Misericórdia (Serviço do Prof. Adolfo Lindenberg) as facilidades que nos permitiram estudar êste caso $e$ os ensinamentos que nos proporcionaram a propósito da parte de dermatologia e micologia. Agradecemos também ao Dr. Carlos da Silva Lacaz, docente de Microbiologia na Fac. Med. Univ. São Paulo (Prof. Floriano de Almeida) que se encarregou da identificação do cogumelo. 
ral direito obrigatório, com o tronco semilevantado e as pernas em semiflexão. Cifose dorsal acentuada. Lesões nódulo-ulcerativas hiperpigmentadas, em parte cicatrizadas e em parte recobertas por crôstas purulentas, nas faces laterais do pescoço. Numerosas lesões ulcerosas, algumas profundamente fistulizadas, disseminadas por todo o tórax, principalmente no esterno e na altura das últimas vértebras dorsais. $\mathrm{Em}$ tôdas, há um halo hipercrômico circundante. $\mathrm{O}$ exame do aparêlho respiratório mostra diminuição de amplitude respiratória dos hemitórax, mais à esquerda; submacicez infraclavicular esquerda; nítido sôpro cavitário nesta região, audível também na suprascapular dêsse lado, além de roncos, estertores crepitantes e subcrepitantes disseminados. $O$ exame do aparêlho circulatório mostra cianose das extremidades e edemas perimaleolares; icto no $5 .^{\circ}$ espaço intercostal esquerdo, um dedo para fora da linha hemiclavicular; prejudicada a delimitação da área de grande macicez cardíaca e do pedículo arterial da base; bulhas muito abafadas em todos os focos; artérias periféricas tortuosas, com paredes endurecidas e ásperas; pulso batendo 92 vezes por minuto, isócrono, fraco e pequeno; pressão arterial, máxima 11 e mínima 7 (manómetro Tycos). Fígado doloroso, com superfície regular, porém bastante aumentado, com o bordo inferior 3 dedos abaixo do rebordo na linha hemiclavicular. Baço percutível. Demais órgãos clìnicamente normais.

Sistema nervoso - Psiquismo íntegro. Equilíbrio e marcha prejudicados. Atrofia dos músculos das pernas, mais nítida à esquerda. Movimentos voluntários e fôrça muscular comprometidos nos membros inferiores, embora não haja paralisia. Reflexos patelares e aquilianos exaltados. Reflexos cutâneo-abdominais e cremastéricos diminuídos. Sinal de Babinski em ambos os pés. Demais reflexos normais, não havendo outros sinais piramidais de libertação. Manobras deficitárias de Barré e Mingazzini prejudicadas em virtude das algias dorsais. Coordenação normal nos membros superiores e prejudicada nos inferiores. Não há distúrbios esfinctéricos. Pesquisa de sensibilidade objetiva prejudicada em vista do mau estado geral do doente.

Exames complementares - Exame microscópico direto do material das fístulas cutâneas $e$ do escarro fresco: positivo para Actinonyces. Cultura: Actinomyces israelli (anaeróbio). Pesquisa do bacilo de Koch no escarro: negativo várias vezes, mesmo com homogeinização. Reação de Wassermann no sangue: negativa. Exame de urina (tipo B): normal. Radiografia dos pulmões: Infiltrações partindo dos hilos e se dirigindo para a esquerda até o ápice, onde se nota um aspecto areolado, e à direita com propagação basal. Infiltração de natureza fibrosclerosante (Rafael de Barros). Radiografia da coluna vertebral e mielografia: Espondilite infecciosa extensa com destruịção parcial dos corpos vertebrais dorsais e acentuada cifose. Osteartrose deformante das últimas vértebras dorsais. Subestenose do canal medular com parada irregular do lipiodol injetado por via suboccipital (Paulo de Almeida Toledo). Exame do líqüido cefalorraquidiano: Punção lombar em decúbito lateral; pressão inicial 15 (manômetro de Claude) ; provas manométricas de Stookey normais; líquor límpido e xantocrômico; citologia 0,4 células por $\mathrm{mm}^{*}$; albumina $4,00 \mathrm{grs}$. por litro; r. Takata-Ara positiva (tipo meningítico); $r$. Wassermann negativa; pesquisa direta de cogumelos, negativa. (O. Lange). Novo exame de líqüido cefalorraquidiano: Punção suboccipital em decúbito lateral; pressão inicial 12 (manômetro de Claude); líquor límpido e incolor; citologia 0,2 células por $\mathrm{mm}^{\mathrm{s}}$; alhumina $0,40 \mathrm{grs}$. por litro; r. Pandy fortemente positiva; r. benjoim 22221.22221 .00000 .0 ; r. Takata-Ara positiva (tipo parenquimatoso); r. Wassermann negativa (O. Lange). Exame otorrinolaringológico: nada de anormal a não ser desvio do septo nasal para a esquerda e palidez acentuada nas mucosas (Antonio Corrêia). Eletrodiagnóstico: Síndrome elétrica de degenerescência parcial nos territórios musculares dependentes do nervo ciático-poplíteo interno de ambos os lados (Lamartine de Assis). 
Evolução e tratamento - Foi tentada, sem qualquer resultado, a terapêutica pelo composto p-aminobenzeno-sulfamida durante 4 meses. A seguir ensaiou-se o tratamento pelo timol (2 grs. diárias), sem resultado. O doente faleceu 6 meses após a internação na enfermaria, em franca caquexia e com acentuada insuficiência cárdio-respiratória.

Necrópsia (SS-19.241) - A necrópsia demonstrou a presença de lesões anatômicas extensas e intensas causadas pelo fungo, com sede pleuropulmonar, cutânea e óssea. O pulmão esquerdo mostra (fig. 1-c), na região apical e no andar médio, um intenso processo cirrótico condensante, com hiperpigmentação antrocótica, em meio da qual existem pequenas cavidades com paredes lisas e contendo material puriforme. A pleura visceral que recobre esta zona apresenta-se fortemente aderente à pleura parietal, exceto na face anterior do lobo superior, onde existe, entre as pleuras, numa área circular de $10 \mathrm{cms}$. de diâmetro, um material de aspecto necrótico, de côr amarelo-enxofre. Nesta altura, a pleura parietal está destruída, achando-se êste material necrótico em contacto direto com os tecidos moles da caixa torácica. O pulmão direito apresenta uma zona de cirrose semeThante àquela do pulmão esquerdo, porém de menores proporções, ocupando apenas a região apical. Nesta zona, existem fortes aderências entre os folhetos pleurais. Nas bases pulmonares, observa-se um pleuriz serofibrinoso correspondendo a 250 cc. de fluido na base direita e $100 \mathrm{cc}$. na base esquerda. $\mathrm{Na}$ parede torácica anterior existem, na pele que recobre o manúbrio e porção próxima do hemitórax esquerdo, uma extensa área cianótica contando numerosos pertuitos fistulosos. Dissecada a pele, verifica-se que êstes últimos penetram os tecidos moles que revestem a grade costal, e ainda põem-se em contacto com as extremidades anteriores da $2 .^{a}$ e $3 .^{a}$ costelas (fig. 1-a). Na parede dorsal, ao nível da coluna sacra, existe outra área extensa de pele cianosada, contendo abertura de pertuitos fistulosos que se aprofundam nos tecidos moles em tôrno da coluna vertebral. $\mathrm{Na}$ região cervical, em ambos os lados, a pele apresenta abertura de trajetos fistulosos que se limitam à pele e tecido celular subjacente, não contraindo relações com gânglios ou outras formações profundas do pescoço.

A coluna vertebral, na região toracolombar, apresenta os corpos vertebrais intensamente infiltrados por um exsudato purulento, amarelo e cremoso. $\mathrm{O}$ tecido ósseo das mesmas é frágil, sendo fàcilmente cortado com faca. Os discos intervertebrais estão poupados. A superfície interna do canal vertebral, numa extensa zona correspondente às últimas vértebras dorsais e às primeiras lombares, apresenta-se corroída e de aspecto bastante irregular. A dura-madre da medula apresenta-se fortemente espessada em tòda a sua extensão e infiltrada pelo exsudato inflamatório em muitos pontos (fig. 1-b). O canal raqueano está permeável em tôda a sua altura. A medula não apresenta lesões. Os tecidos moles que circundam a coluna toracolombar apresentam-se difusamente infiltrados pelo exsudato inflamatório.

O exame microscópico demonstrou, em tôdas as partes acometidas, a presença dos grãos de Actinomyces rodeados pela reação granulomatosa defensiva. As lesões vertebrais caraterizavam-se, além disso, pelas extensas zonas de destruição óssea. (Figs. 2 e 3 ).

\section{COMENTARIOS}

O estudo anátonæ-patológico dêste caso demonstra tratar-se de uma actinomicose, cujas lesões mais antigas têm como sede ambos os pulmões, constituindo, portanto, a forma anátomo-clínica de actinomicose pulmonar. $\mathrm{Na}$ sua marcha evolutiva, o processo infeccioso, após produzir lesões de caráter prevalentemente cirrótico em ambos os pulmões, propagou-se para a parede torácica, invadindo os tecidos moles e vér- 


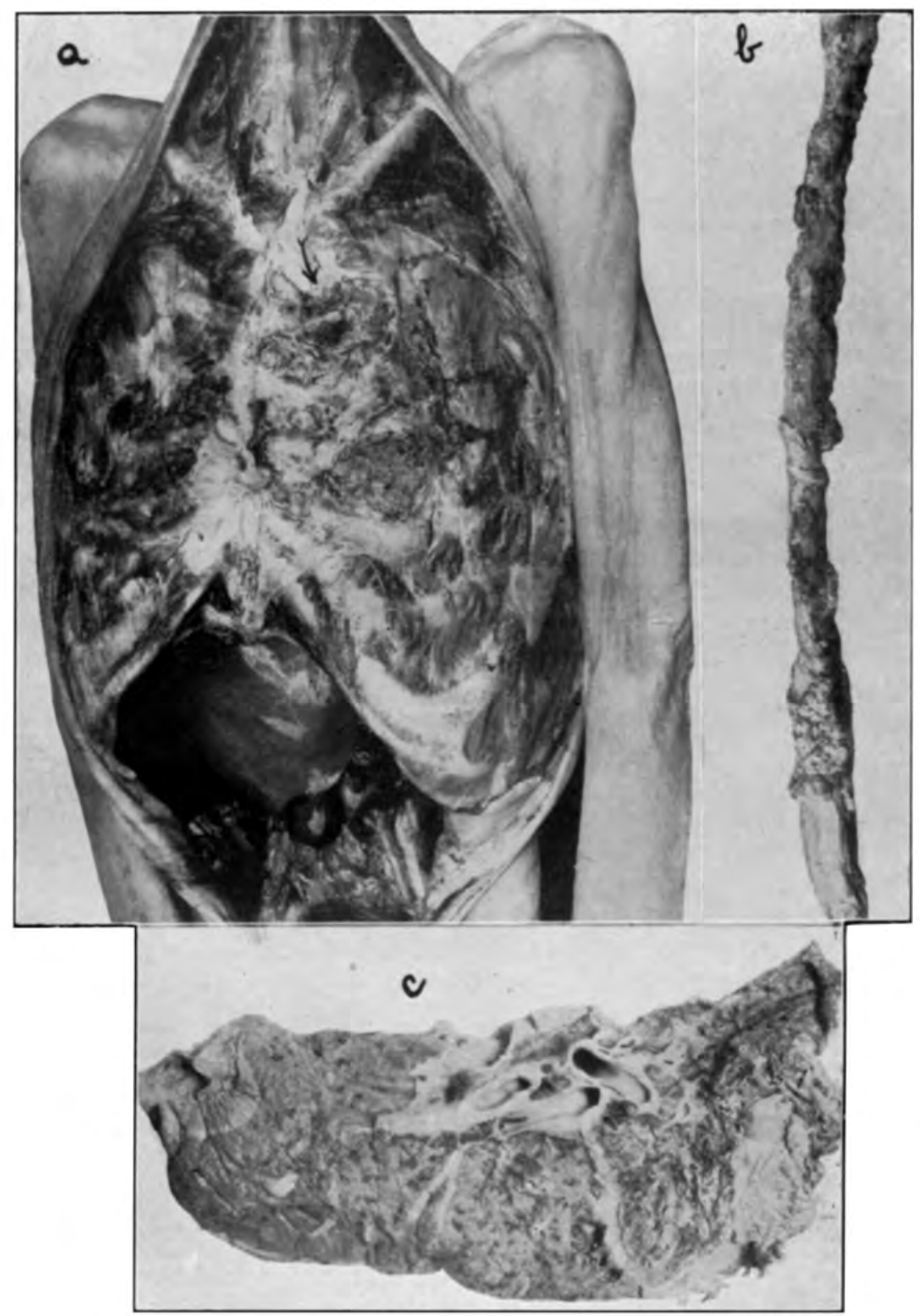

Fig. 1 - Em a, na zona apontada pela flecha, fístulas abertas na pele, que se propagam para a espessura dos tecidos moles locais, produzindo lesōes nas extremidades anteriores das $3 .^{a}$ e $4 .^{a}$ costelas. Em $b$, medula revestida da dura-máter, a qual se apresenta irregularmente espessada pelo processo inflamatório. Em $c$, corte do pulmão esquerdo, mostrando, no lobo superior, extenso processo de fibrose associado a pequenas cavidades. 


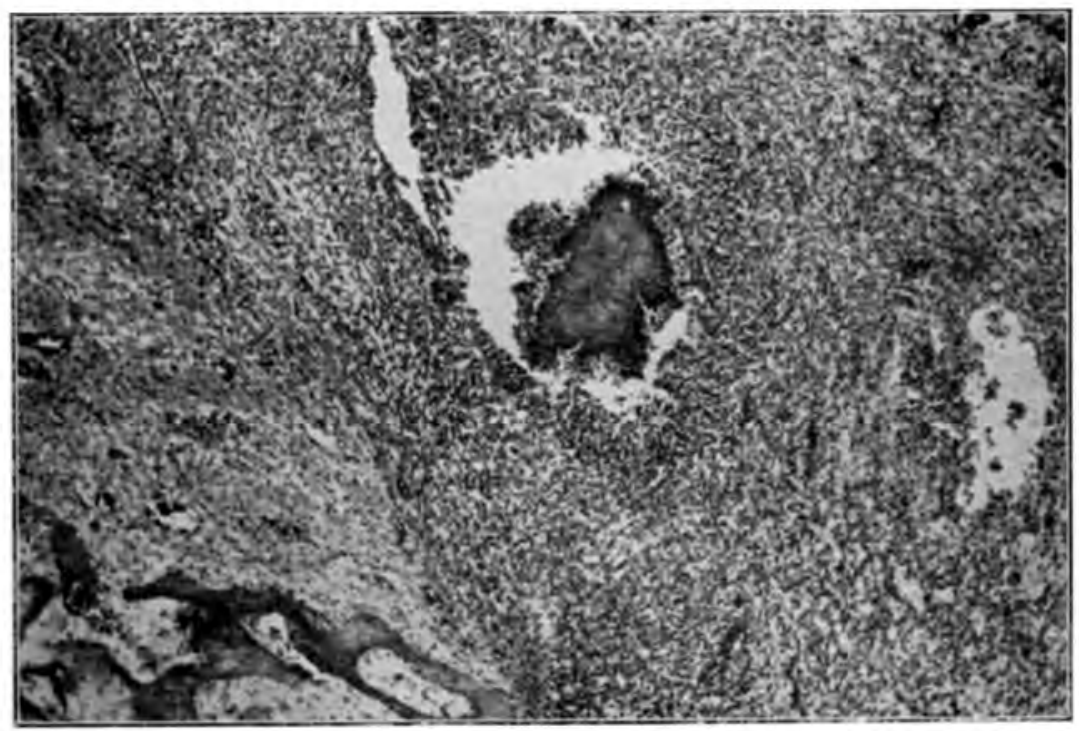

Fig. 2 - Na metade esquerda: tecido ósseo de um corpo vertebral, notando-se traves ósseas em meio de un tecido fibroso. $\mathrm{Na}$ metade direita: destruição total do tecido ósseo c substituição pelo tecido inflamatório que rodeia $\mathrm{um}$ grão actinomicótico.

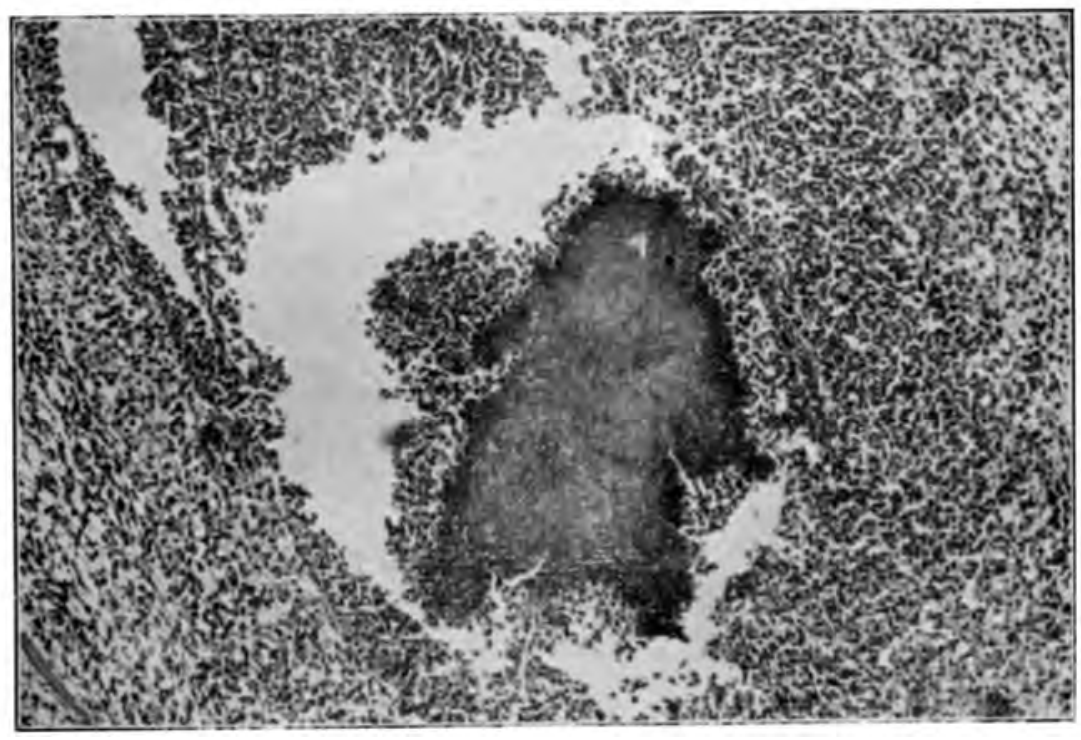

FIG. 3 - Grande aumento do grão actinomicótico visto na figura 1, rodeado de neutrófilos e, mais externamente, por uma faixa fibrosa. 
tebras, estabelecendo trajetos fistulosos que se foram abrir na pele da face anterior do tórax. $€$ bastante plausível que a propagação das lesões do pulmão à caixa torácica se tenha processado por contigüidade, através da solução de continuidade da pleura parietal esquerda, situada na face anterior do lobo superior. Com efeito, estas lesões secundárias se manifestam mais intensas justamente nessa altura. A infecção, ainda por contigüidade, infiltra os sentidos moles que rodeiam a coluna vertebral toracolombar e agride o tecido ósseo dos corpos vertebrais, resultando uma extensa osteomielite actinomicótica. Propagando-se às partes ósseas mais profundas, alcança o espaço epidural e invade a duramadre medular, espessando-a e infiltrando-a, sem, contudo, produzir lesões anatômicas obstrutivas que impedissem a livre passagem do líqüido cefalorraquidiano, e poupando também a própria medula.

Trata-se, portanto, de um caso interessante sob o ponto de vista anátono-patológico devido ao fato de se estabelecerem, em modalidade toracopulmonar da doença, lesões secundárias extensas de osteomielite da coluna e de meningite medular específicas. Além dêstes particulares interessantes de ordem anátomo-patológica, devem ser ressaltadas, como um fato raro, as manifestações clínicas de caráter neurológico resultantes das lesões vertebrais e meníngeas. Estas acarretaram um quadro radiculomedular compressivo, clìnicamente frusto. Não há, na literatura nacional, qualquer observação referente a esta complicação nervosa produzida por Actinomyces. Trata-se do primeiro caso de Cohnistreptotrix israelli isolado em S. Paulo, e quiçá no Brasil. Interessante foi a desproporção entre as síndromes liquórica e neurológica; realmente, enquanto o quadro clínico fôra discréto, o liquórico foi muito intenso, máxime o lombar. Este evidenciou a síndrome de Froin. No entanto, as provas manométricas de Stookey não indicaram qualquer bloqueio, em contraposição ao resultado da mielografia descendente (bloqueio parcial com parada transitória do lipiodol, em gôtas). O líquiido colhido por via suboccipital mostrou-se nitidamente diverso daquele extraído por via lombar, apresentando taxa quase normal de albuminas, porém, com reações coloidais de tipo parenquimatoso, o que não existia no líquor lombar. Tais aspectos liquóricos e mielográfico confirmavam a existência de leptomeningite crônica espinhal; esta, ao lado das lesões ósseas vertebrais e deformação da coluna, era responsável pela compressão das raízes e da medula.

\section{RESUMO}

Os Autores apresentam um caso de actinomicose primitivameste pleuropulmonar, em que ocorreu, provàvelmente por contigüidade, a propagação do processo à parede torácica. Infiltrados os tecidos que rodeiam a coluna toracolombar, produziu-se extensa osteomielite ver- 
tebral actinomicótica; a dura-madre foi afetada, espessou-se e produziu uma síndrome, clínicamente frusta, de compressão radiculomedular. Não houve lesões anatômicas que determinassem bloqueio total do canal raqueano. Não há referência, na literatura nacional, a esta complicação nervosa da actinomicose, sendo, também, a primeira vez que a espécie Cohnistreptotrix israelli foi isolada em São Paulo, e talvez no Brasil.

\section{SUMMARY}

The authors report a case of actinomycosis with primitive site in the pleura and lungs, which probably by contiquity involved the thoracic wall. The tissues surrounding the thoracolumbar column have been affected, originating extensive vertebral actinomycotic osteomyelitis; the sickening of the dura caused a mild syndrome of radiculospinal compression; there were no anatomic changes producing total spinal block. There is no reference, in Brazilian literature, to this nervous complication of actimycosis, and it is the first time the species Cohnistreptotrix israelli has been found in São Paulo, perhaps in Brazil.

Rua Albuquerque Lins, 904 - São Paulo. 